http://jmscr.igmpublication.org/home/

ISSN (e)-2347-176x ISSN (p) 2455-0450

crossref DOI: https://dx.doi.org/10.18535/jmscr/v8i5.39

Journal Of Medical Science And Clinical Research

IGM Publication

An Official Publication of IGM Publication

\title{
Socio-demographic and clinical profile of patients with major depressive disorder attending psychiatric OPD
}

\author{
Authors \\ Ajaz Ahmad Suhaff ${ }^{1}$, Sajid Mohammad Wani*1, Abdul Wahid Khan ${ }^{2}$, \\ Bilal Ahmad Teli ${ }^{3}$ \\ ${ }^{1}$ Senior Resident Department of Psychiatry SKIMS Medical College Bemina \\ ${ }^{2}$ Prof. \& Head of the Department, Department of Psychiatry SKIMS Medical College Bemina \\ ${ }^{3}$ Clinical Psychologist Department of Psychiatry SKIMS Medical College Bemina \\ *Corresponding Author \\ Sajid Mohammad Wani \\ Senior Resident Department of Psychiatry SKIMS Medical College Bemina, India
}

\begin{abstract}
Introduction: Depression is one of the most common mental disorders which decreases the quality of life and causes burden for individual, families and society. It is estimated that by the year 2020 it would be the second leading cause of disability-adjusted life years (DALYs), second only to ischemic heart disease.

Material and Methods: This was a prospective study design. The study was conducted in the department of Psychiatry Sher-I- Kashmir Institute of Medical Sciences (SKIMS) Medical College and Hospital, Bemina, Jammu and Kashmir. The study was approved by the SKIMS Ethical Committee. The study sample comprised of 200 patients diagnosed with first episode depression (Major depressive disorder) attending psychiatric outpatient department and diagnosed by using DSM 5 criterion. The severity of the depression was assessed by HAM-D scale. Patients satisfying the inclusion and exclusion criteria during the study period were screened.

Results: In our study majority of our patients81 (42.4\%) were aged between 18-29 years, The mean age was 35.3 \pm 13.56. Males constituted 106 (55.5\%), 101 (52.9\%) patients who belonged to rural areas and 90 (47.1\%) were from urban areas, 98 (51.3\%) were uneducated. There were 104 (54.5\%) married men and $119(62.3 \%)$ patients in our study belonged to middle socioeconomic class.

Conclusion: Clinical profile revealed that most of the patients had mild to moderate form of depression, a few also reported severe form of depression. Careful diagnosis of depression can help in early starting of treatment so that it can greatly decrease morbidity in patients

Keywords: Depression, Socio-demographic profile, clinical profile, Kashmir.
\end{abstract}

\section{Introduction}

Depression is one of the most common mental disorders which decreases the quality of life and causes burden for individual, families and society. It is estimated that by the year 2020 it would be the second leading cause of disability-adjusted life years (DALYs), second only to ischemic heart disease. ${ }^{[1-4]}$ Mental health survey indicated that 10$15 \%$ of population in their lifetime experience major depression. ${ }^{[5]}$ It has been reported that in a given year 5\% suffer from major depressive disorder \& lifetime prevalence of all depressive 
disorders taken together is over $20 \% .{ }^{[6]}$ In India a survey reported an overall prevalence of $15.9 \%$ for depression. ${ }^{[7]}$ The prevalence of depression has increased over past few decades. ${ }^{[8]}$ The prevalence of depressive symptoms in Kashmir as measured by CES-D scale was reported approximately $55.72 \% .{ }^{[9]}$ In Kashmir there has been political ups and downs and continuous violence since three decades which may result in high psychiatric morbidities ${ }^{[10]}$

In this paper, we present the details of our study findings on the sociodemographics and clinical profile of patients suffering from depressive disorders attending our hospital Out Patient Department.

\section{Aims and Objectives}

To study the socio-demographic and clinical profile of patients with major depressive disorder attending psychiatric OPD.

\section{Materials and Methods}

This was a prospective study design. The study was conducted in the department of Psychiatry Shere-I- Kashmir Institute of Medical Sciences (SKIMS) Medical College and Hospital, Bemina, Jammu and Kashmir. The study was approved by the SKIMS Ethical Committee. The study sample comprised of 191 patients diagnosed with Major depressive disorder attending psychiatric outpatient department diagnosed by using DSM 5 criterion during the period of one year. The severity of the depression was assessed by HAMD scale. Patients satisfying the inclusion and exclusion criteria during the study period were screened.

\section{Inclusion Criteria}

1. Patients above 18 years of age.

2. Patients with major depressive disorder (MDD).

3. Those able to understand and answer proforma questionnaire verbally.

4. Those willing to participate and give informed consent.

\section{Exclusion Criteria}

1. Patients $<18$ years of age.

2. Patients with depression with psychotic features.

3. Patients with bipolar affective disorder.

4. History of substance abuse or dependence.

5. Patients unable to understand and answer proforma questionnaire verbally

6. Those not willing to participate or give informed consent.

The purpose of the study was explained to the patients. It was also explained that the participating in this study or withdrawing from the study at any stage, would in no way affect the treatment. Participants written informed consent was taken in his/her own language prior to taking the information. If the patient was illiterate, the consent form was read by the relatives and the consent was taken. After written informed consent each patient was individually interviewed along with the proforma prepared specifically for the study to gather information on parameters pertaining to sociodemographic and clinical profile. The anonymity of the participants was ensured, as the names of the participants were not written on any of the questionnaires, which were assigned a number only, and confidentiality of data were strictly maintained. Care was also taken that no harm came to the patients, by ensuring privacy whilst completing the interview.

\section{Instruments}

Semi-Structured Proforma: Proforma was prepared for the study which included socialdemographic profile, Clinical profile (including history of present complaints medical and psychiatric, Family and Personal history and clinical examination and diagnosis.

DSM-5: Diagnostic and Statistical Manual of Mental Disorders Fifth Edition was used for the diagnosis of depression. DSM-5 diagnostic criteria has been used for diagnosing the patients having depression. ${ }^{[1]}$ DSM-5 diagnostic criterion is a tool for collecting and communicating accurate public health statistics on mental 
disorders. DSM-5 is designed better to fill the need of clinicians, patients, families, and researchers for a clear and concise description of each mental disorder organized by explicit diagnostic criteria supplemented. Diagnosis was formulated under the supervision of the consultant in the department.

\section{Hamilton Depression Rating Scale- HAM-D}

Hamilton Depression Rating scale (HAM-D) has been used for assessing the severity of depression. The Ham-D is the most widely used clinicianadministered depression assessment scale. A score of $0-7$ is generally accepted to be within the normal range, 8-13-mild depression, 14-18moderate depression, 19-22-severe depression. ${ }^{[12]}$ At baseline HAM-D scale was applied, then after 6 and 12 weeks follow up. Response to treatment was measured by the change in HAM-D scores before and after treatment, with positive values reflecting improvement in HAM-D symptoms.

\section{Statistical Analysis}

All data thus collected was tabulated and analysed statistically using SSPS software version 20.0 under guidance of a statistician and conclusions were drawn.

\section{Results}

\begin{tabular}{|l|c|c|}
\hline \multicolumn{3}{|c|}{ Age distribution of studied patients } \\
\hline Age (years) & No. of Patients & Percentage \% \\
\hline $18-29$ & 81 & 42.4 \\
\hline $30-39$ & 42 & 22.0 \\
\hline $40-49$ & 26 & 13.6 \\
\hline $50-59$ & 38 & 19.9 \\
\hline$\geq 60$ & 4 & 2.1 \\
\hline Mean \pm SD $=35.3 \pm 13.56$ & \\
\hline
\end{tabular}

\begin{tabular}{|l|c|c|}
\hline \multicolumn{3}{|l|}{ Gender distribution of patients } \\
\hline Gender & No. of Patients & Percentage \% \\
\hline Male & 106 & 55.5 \\
\hline Female & 85 & 44.5 \\
\hline Total & 191 & 100 \\
\hline
\end{tabular}

\begin{tabular}{|l|c|c|}
\hline \multicolumn{3}{|l|}{ Distribution of patients as per residence } \\
\hline Residence & No. of Patients & Percentage\% \\
\hline Rural & 101 & 52.9 \\
\hline Urban & 90 & 47.1 \\
\hline Total & 191 & 100 \\
\hline
\end{tabular}

\begin{tabular}{|l|c|c|}
\hline \multicolumn{3}{|l|}{ Occupation of studied patients } \\
\hline Occupation & No. of Patients & Percentage \% \\
\hline Student & 15 & 7.9 \\
\hline Unemployed & 97 & 50.8 \\
\hline Employed & 79 & 41.4 \\
\hline Total & 191 & 100 \\
\hline
\end{tabular}




\begin{tabular}{|l|c|c|}
\hline \multicolumn{3}{|l|}{ Educational status of studied patients } \\
\hline Educational status & No. of Patients & Percentage \% \\
\hline Uneducated & 98 & 51.3 \\
\hline Primary & 8 & 4.2 \\
\hline Middle & 16 & 8.4 \\
\hline Matric & 29 & 15.2 \\
\hline Graduate & 32 & 16.8 \\
\hline Postgraduate & 8 & 4.2 \\
\hline Total & 191 & 100 \\
\hline
\end{tabular}

\begin{tabular}{|l|c|c|}
\hline \multicolumn{3}{|l|}{ Marital status of studied patients } \\
\hline Marital Status & No. of Patients & Percentage \% \\
\hline Married & 104 & 54.5 \\
\hline Unmarried & 73 & 38.2 \\
\hline Widow & 7 & 3.7 \\
\hline Divorcee & 7 & 3.7 \\
\hline Total & 191 & 100 \\
\hline
\end{tabular}

\begin{tabular}{|l|c|c|}
\hline \multicolumn{3}{|l|}{ Socio economic status of studied patients } \\
\hline Socio economic status & No. of Patients & Percentage \% \\
\hline Upper Class & 15 & 7.9 \\
\hline Middle Class & 119 & 62.3 \\
\hline Lower Class & 57 & 29.8 \\
\hline Total & 191 & 100 \\
\hline
\end{tabular}

\begin{tabular}{|l|c|c|c|c|c|}
\hline Showing HAMD Score in patients before and after treatment \\
\hline \multirow{2}{*}{ HAMD Score } & \multirow{2}{*}{ Mean } & \multirow{2}{*}{ SD } & \multicolumn{3}{|c|}{ Paired Samples test } \\
\cline { 4 - 6 } & & & Comparison & $\begin{array}{c}\text { Paired } \\
\text { Difference }\end{array}$ & P-value \\
\hline Pre Treatment (I) & 13.34 & 3.080 & I vs II & 2.1 & $<0.001^{*}$ \\
\hline After 6 weeks (II) & 11.24 & 2.742 & I vs III & 3.38 & $<0.001^{*}$ \\
\hline After 12 weeks (III) & 9.96 & 2.335 & II vs III & 1.28 & $<0.001^{*}$ \\
\hline
\end{tabular}

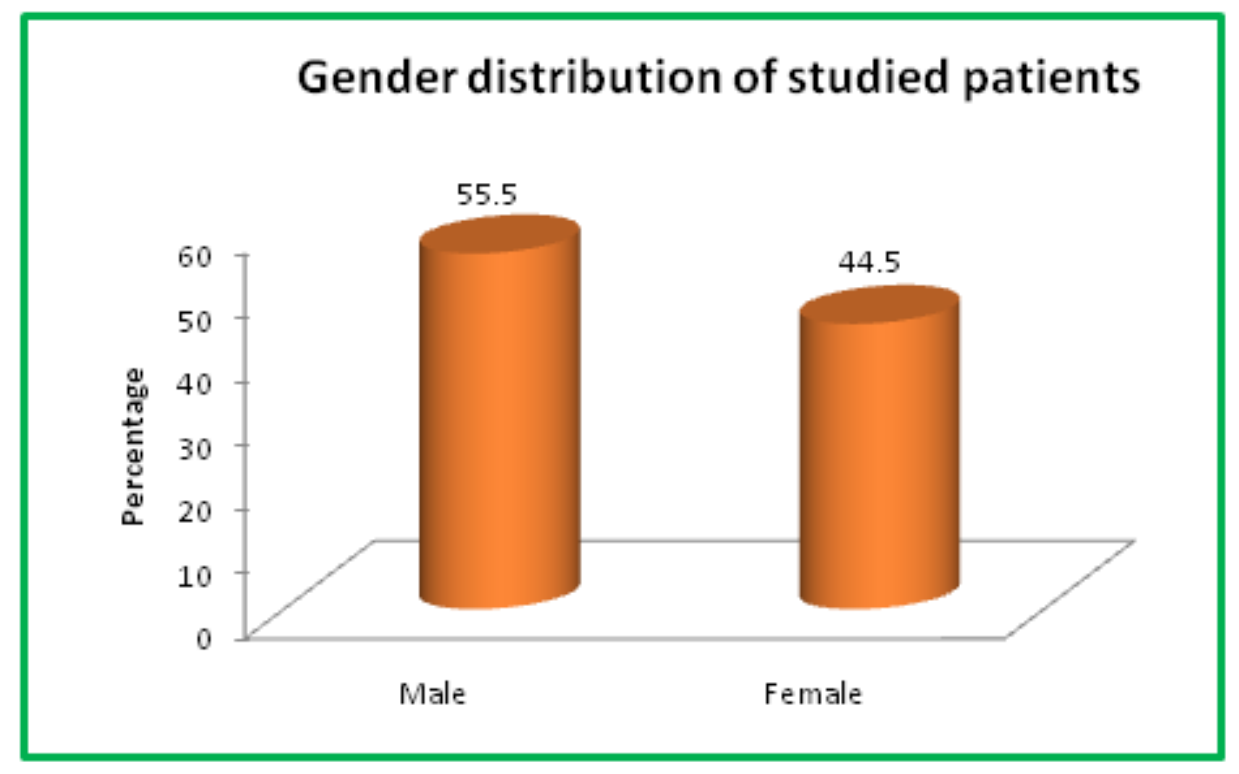



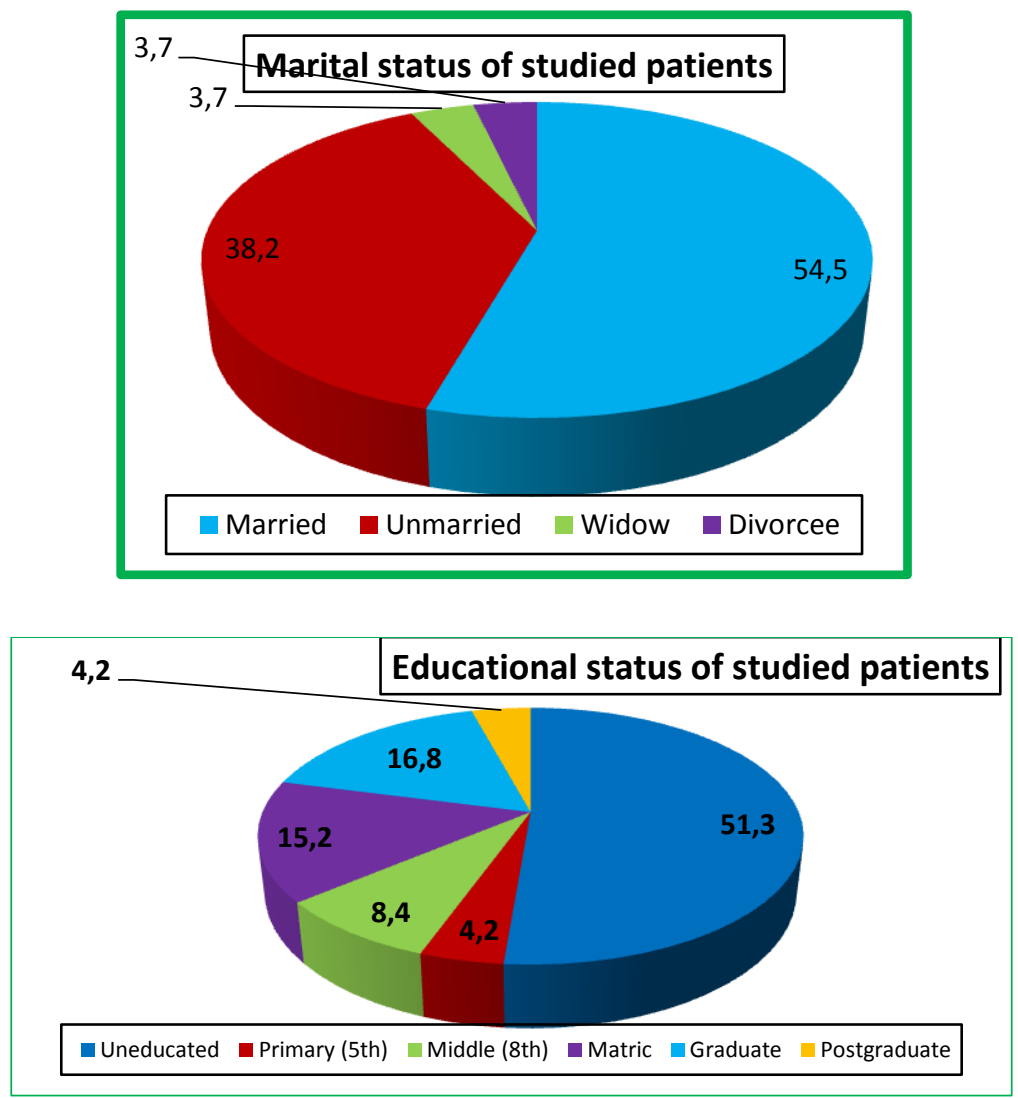

\section{Showing HAMD Score in patients before and after treatment}

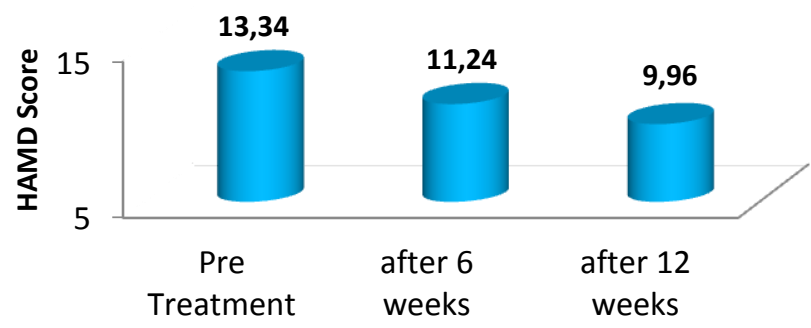

In our study majority of our patients $81(42.4 \%)$ were aged between 18-29 years, $42(22.0 \%)$ were $30-39$ years of age, 26 (13.6\%) were aged between 40-49, 38 (19.9) were aged between 50-59, and only $4(2.1 \%)$ patients were more than 60 years. The mean age was $35.3 \pm 13.56$. Males constituted $106(55.5 \%)$ while as there were $85(44.5 \%)$ females out of a total of 191 patients. Majority of our studied population 101 (52.9\%) who belonged to rural areas and $90(47.1 \%)$ were from urban areas.

In our study that Out of 191 patients, 98 (51.3\%) were uneducated, $8(4.2 \%)$ patients were primary pass, $16(8.4 \%)$ were middle pass, $29(15.2 \%)$ were matriculates, $32(16.8 \%)$ were graduates, and $8(4.2 \%)$ were postgraduates and $97(50.8 \%)$ were 
unemployed, 79 (41.4\%) were employed and 15 (7.9\%) were students. There were $104(54.5 \%)$ married men and women in our study, $73(38.2 \%)$ were unmarried, $7(3.7 \%)$ each were widowed and divorcee. $119(62.3 \%)$ patients in our study belonged to middle socioeconomic class, 57 (29.8\%) patients were from lower class and 15 (7.9\%) patients were belonging to upper socioeconomic class. There were only 38 (19.9\%) patients in our study who had family history of psychiatric illness while as $153(80.1 \%)$ were not having any family history of psychiatric illnesses. The mean pre-treatment HAM-D score in patients was 13.34, after 6 weeks the mean HAM-D score was 11.24 and after 12 weeks the HAM-D score was 9.96.

\section{Discussion}

Depressive disorders are among the most common mental health problems and is related to reduced quality of life. ${ }^{[13-14]}$ In our study, mean age was $35.3 \pm 13.56$ years and majority of our patients 81 $(42.4 \%)$ were aged 18-29 years, $42(22.0 \%)$ patients were 30-39 years of age, 26 (13.6\%) were aged 40-49, 38 (19.9) were aged between 50-59, and only $4(2.1 \%)$ patients were more than 60 years. It has been observed that depression is more prevalent in this age group. Another reason could be younger patients are readily seeking help for their psychological problems than older people. Similar age distribution was observed by Rajiv et al. ${ }^{[15]}$ in their study where the mean age of the studied subjects was $37.46 \pm 13.56$ yr. Gitlin et al. in their study observed similar results where the mean age of studied subjects was 37.6 with standard deviation $9^{[16]}$. Another study conducted by Shoib et al. ${ }^{[17]}$ where maximum number of the patients were in the age group of 31-40 years 198 (36.9\%) followed by 21-30 years $154(28.7 \%)$ followed by 41-50 years 128 (23.9\%), then 51-60 years $39(7.3)$ followed by $\leq 2014(2.6 \%)$ and least was in $61-70$ age group $4(0.7 \%)$. The mean age of the patients was $35.85 \pm 9.475$.In our study, out of 191 patients, males constituted $106(55.5 \%)$ while as $85(44.5 \%)$ were females. There is only a marginal difference between the genders. In our state females usually approach faith healers. In India males have more access to health care system than the females. In addition to it due to the prevailing situation in Jammu and Kashmir, males can be more prone and vulnerable to suffer from depression. Our results were similar to the study conducted by Rajiv et al. in which males were $50.4 \%$ and females were $49.3 \%$.In our study $101(52.9 \%)$ patients belonged to rural areas and $90(47.1 \%)$ were from urban areas. Though the majority of patients were from rural areas but relatively the percentage of patients from urban areas was higher, the reason could be the catchment area of the hospital which is in the urban dwelling. Study conducted by Maqbool et al. ${ }^{[18]}$ observed almost similar results that majority of patients belonging to rural areas was $57.14 \%$ and patients who belong to urban areas were $42.8 \%$ which were close to our study. Probst et al. ${ }^{[19]}$ also found that the prevalence of depression is significantly higher in residents of rural areas compared to urban areas $6.1 \%$ versus $5.2 \%$. Shoib et al in his study also observed that majority of patients belong to urban $189(35.19 \%)$ as compared to rural $348(64.80 \%)$.In our study, Out of 191 patients, $98(51.3 \%)$ were uneducated, 8 (4.2\%) patients were primary pass, $16(8.4 \%)$ were middle pass, $29(15.2 \%)$ were matriculates, $32(16.8 \%)$ were graduates and $8(4.2 \%)$ were postgraduates. The reason could be that, as per census of India (2011), Jammu and Kashmir is one of the states of India where literacy rate is 67.16 which is almost in accordance with our observations. Sarmila Mallik et al. ${ }^{[20]}$ observed in their study that most of the depression patients (67.9\%) were illiterate. Maqbool et al. found almost similar results in their study Illiterate 205 (37.7\%), Primary 79 (14.7\%), Secondary 106 (19.7\%), Matric 73 (13.6\%), Graduate 66 (13.3\%) and Postgraduate 8 (1.5\%). In our study, 97 $(50.8 \%)$ patients were unemployed, 79 (41.4\%) were employed and 15 (7.9\%) were students. Most of the people who visit government hospitals of our valley for free treatment are uneducated and 
unemployed. As educated and employed seek treatment from private hospitals and clinics and also unemployment can be one of the risk factors for depression.

In our study, the majority of patients 104 (54.5\%) were married and 73 (38.2\%) were unmarried, 7 $(3.7 \%)$ were widowed and $7(3.7 \%)$ were divorcee. Usually maximum number of population in Indian subcontinent is married in this age group. Another reason could be that married people are overburdened by responsibilities. Sarmila et al. in their study found that majority of depression patients $(70.5 \%)$ were married. Shoib et al found that majority of their studied patients $66.7 \% 358$ patients were married, $26.3 \%$ patients were unmarried, $4.1 \%$ were widowed and $3 \%$ were separated. In our study as for as socioeconomic status is concerned, majority of patients $119(62.3 \%)$ belonged to middle socioeconomic class, $57(29.8 \%)$ patients belonged to lower socio-economic class and 15 (7.9\%) patients were from upper socio economic class. Shoib et al. found that majority of their patients were from lower socioeconomic status 300 (65.44\%), $178(33.13 \%)$ from middle, and 9 $(1.67 \%)$ from upper socioeconomic status, as majority of population in our state is from lower and middle socioeconomic class. In our study there were $38(19.9 \%)$ patients who had family history of psychiatric illness (panic disorder, generalized anxiety disorder, phobia) while as 153 $(80.1 \%)$ were not having any family history of psychiatric illness.

In our study the mean pre-treatment HAM-D score was $13.34 \pm 3.08(\mathrm{P}<0.001)$ and mean HAMD score after treatment (6 weeks) was $11.24 \pm 2.74$ $(p<0.001)$ and after 12 weeks was $9.96 \pm 2.33$ $(\mathrm{p}<0.001)$, which was statistically significant. Decrease in HAM-D score reflects improvement in symptoms with treatment. Gitlin et al. in their study also observed the mean HAM-D score before treatment was 20.7 (SD 1, range 14-31) and after treatment, the mean HAM-D score was 7.8 (SD 1.4, range 0-18). Zhou et al. in their study revealed that the 8 weeks treatment decreased the HAMD scores. ${ }^{\text {[21] }}$

\section{Conclusion}

Majority of the participants were males, predominantly belonging to age group of 18-29 years, mostly having education up to middle school, working in semi-skilled or unskilled group and married. Clinical profile revealed that most of the patients had mild to moderate form of depression, a few also reported severe form of depression. Some of them had given family history of psychiatric illness. The Hamilton Depression Rating Scale-(HAM-D) analysis pointed towards presence of depression with mean score of 13.34 before start of treatment and 11.24 and 9.96 respectively after6 and 12 weeks of treatment.

When the HAMD scores were compared with the treatment, most of the patients had lower scores. Treatment of patients decreased HAM-D score, which reflects improvement in symptoms. Careful diagnosis of depression can help in early starting of treatment so that it can greatly decrease morbidity in patients.

\section{Source of Support: Nil \\ Conflict of Interest: None}

\section{References}

1. World Health Organization Prevention and promotion in mental health Geneva. 2002.

2. D'Alisa S, Miscio G, Baudo S, Simone A, Tesio L, Mauro A. Depression is the main determinant of quality of life in multiple sclerosis: a classification-regression (CART) study. Disabil Rehabil. 2006; 28: 307-314. .

3. Fruhwald S, Loffler H, Eher R, Saletu B, Baumhackl U. Relationship between depression, anxiety and quality of life: a study of stroke patients compared to chronic low back pain and myocardial ischemia patients. Psychopathology. 2001; 34:50-56. 
4. Lopez AD, Mathers CD, Ezzati M, Jamison DT, Murray CJ. Global Burden of Disease and Risk Factors. Washington: The World Bank; 2006.

5. Bromet E, Andrade LH, Hwang I, Sampson NA, Alonso J, de Girolamo G, et al. Cross national epidemiology of DSMIV major depressive episode. BMC Med 2011; 9: 90.

6. Murphy JM, Laird NM, Monson RR, Sobel AM, Leighton AH. A 40-year perspective on the prevalence of depression: the Stirling County Study. Arch Gen Psychiatry 2000; 57: 209-15.

7. Poongothai S, Pradeepa R, Ganesan A, Mohan V. Prevalence of depression in a large urban South Indian population - The Chennai Urban Rural Epidemiology Study (CURES-70). PloS One 2009; 4: E7185.

8. Nandi DN, Banerjee G, Mukherjee SP, Ghosh A, Nandi PS, Nandi S. Psychiatric morbidity of a rural Indian community changes over a 20 year interval. British $\mathbf{J}$ Psychiatry 2000; 176: 351-6.

9. Syed Amin, A.W. Khan. Life in conflict: Characteristics of Depression in Kashmir. Int J Health Sci (Qassim). 2009 Jul; 3(2): 213-223.

10. Mushtaq R, Shoib S, Shah T, Mushtaq S. Tryptophan hydroxylase 2 gene polymorphism in anxiety and depressive disorder in kashmiri population. Journal of Clinical and Diagnostic Research. 2014;8: WC01-WC03.

11. American Psychiatric Association. Diagnostic and Statistical Manual of Mental Disorders. 4th ed. Washington: The Association; 1994.

12. Hamilton M (1980) Rating depressive patients. J Clin Psychiatry 41:21-24.

13. Kessler RC, Chiu WT, Demler O, Merikangas KR, Walters EE. Prevalence, severity, and comorbidity of 12-month DSM-IV disorders in the National Comorbidity Survey Replication. Arch
Gen Psychiatry 2005;62(6):617-27. Erratum in Arch Gen Psychiatry 2005; 62(7):709.

14. McKenna MT, Michaud CM, Murray CJ, Marks JS. Assessing the burden of disease in the United States using disabilityadjusted life years. Am J Prev Med 2005;28(5):415-23.

15. Rajiv Radhakrishnan, Sam Calvin, Jyotin Kshitiz Singh, Binston Thomas \& Krishnamachari Srinivasan .Thyroid dysfunction in major psychiatric disorders in a hospital based sample; Indian J Med Res 138, December 2013, pp 888-89.

16. Gitlin M, Altshuler LL, Frye MA, Suri R, Huynh EL, Fairbanks 2. L, et al. Peripheral thyroid hormones and response to selective serotonin reuptake inhibitors. J Psychiatry Neurosci 2004; 29: 383-6.

17. Sheikh Shoib, Raheel Mushtaq, Mohammad Maqbool Dar, Tasleem Arif, Tabindah Shah, Tajamul Hussain, Mohammad Saleem Sharoo; Psychiatric Manifestations in thyroid disorders. International Journal of Clinical Cases and Investigations 1st October 2013. Volume 5 (Issue 3),84:98.

18. Mohammad Maqbool Dar, Sheikh Shoib, Haamid Bashir, Mohammad Hayat Bhat, Waseem Hassan Ahangar. Link between Psychiatric and Autoimmune Thyroid Disorder. International Journal of Health Sciences \& Research February 2013 Vol.3; Issue: 2.

19. Probst JC, Laditka SB, Moore CG, Harun N, Powell MP, Baxley EG. Rural-urban differences in depression prevalence: implications for family medicine. Fam Med. Oct 2006; 38(9):653-60.

20. Sarmila Mallik, Abhik Sinha, Prasanta Kumar Das, Sanchari Roy, Kanti Bhushan Choudhury, Asish Mukhopadhyay. Anxiety and Depression: Their Epidemiological Factors----A Study on The Patients Attending Psychiatric OPD of 
a Teaching Hospital, Kolkata, West Bengal. IOSR Journal of Dental and Medical Sciences. Aug. 2014 Volume 13, Issue 8 Ver. I, P 26-29.

21. Zhenhe Zhou, Suxia Cao, Hengfen Li, Youhui Li; Treatment with escitalopram improves the attentional bias toward negative facial expressions in patients with major depressive disorders. Journal of Clinical Neuroscience October 2015. Volume 22, Issue 10, Pages 1609-1613. 